\title{
A Surface Roughness Predictive Model FOR DSS LONGITUDINAL TURNING OPERATION
}

\author{
PAWAN K. \& MISRA, J. P.
}

Abstract: The present study proposed an improved predictive model for surface roughness of DSS turned part. The effect of various input process parameter namely cutting speed, feed rate, and approach angle is taken into consideration for the developed model. Longitudinal runs were conducted using the L9 orthogonal array on a lathe machine. Analysis of variance was also employed to investigate the contribution and effects of cutting parameters on response characteristics. The results revealed that the feed rate was the most influential factor followed by cutting speed and approach angle. Among the developed models, Model-2 found having a better adequacy (98.15\%) than the Model-1 (85.25\%) for surface roughness prediction.

Key words: Taguchi approach, feed, ANOVA, surface roughness, duplex stainless steel
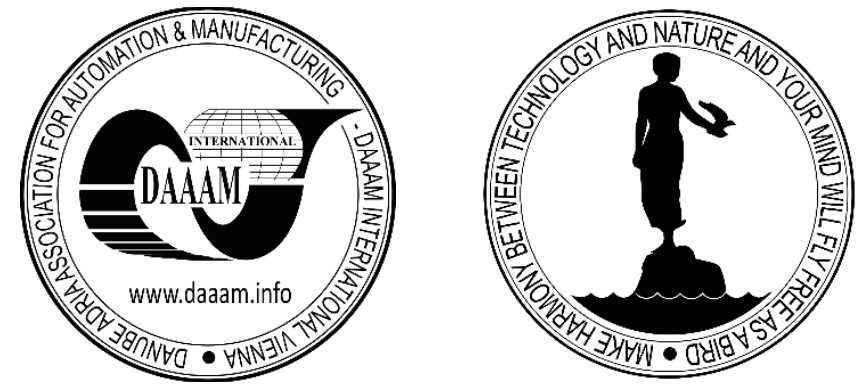

Authors' data: Pecujlija, Kumar, P[awan] \& Misra, [J.][P.], National Institute of Technology Kurukshetra, H.NO.F-80, NIT CAMPUS 136119, Kurukshetra, India, pawank76@gmail.com,joyprakash.misra@gmail.com

This Publication has to be referred as: Pawan, K[umar] \& Misra, J[oy] P[rakash] (2018). A Surface Roughness Predictive Model for DSS Longitudinal Turning Operation, Chapter 25 in DAAAM International Scientific Book 2018, pp.285-296, B. Katalinic (Ed.), Published by DAAAM International, ISBN 978-3-902734-19-8, ISSN 1726-9687, Vienna, Austria

DOI: 10.2507/daaam.scibook.2018.25 


\section{Introduction}

Duplex stainless steels (DSSs) having a wide range of applications due to a favorable combination of properties. DSSs are extensively being used in many industrial sectors like desalination, chemical tankers, pressure vessels, storage tanks, machinery in the pulp and paper industry, and also in civil engineering applications. They have higher contents of chromium and lower contents of nickel and molybdenum and they are excellent engineering materials [1]. Duplex stainless steel (DSS) combines the benefits of both ferritic stainless steel (FSS) and austenitic stainless steel (ASS) by proper balancing of ferrite and austenite. But, their machinability is more difficult compared to other alloy steels due to low thermal conductivity, high built-up edge (BUE) formation tendency and high deformation hardening.

Surface roughness plays an important role as it influences the fatigue strength, wear rate, coefficient of friction, and corrosion resistance of the machined components. Turning is most commonly used in traditional machining processes to machine titanium alloys. Cutting speed, feed rate, depth of cut, features of tools, workpiece material, and coolant conditions are the cutting parameters which highly affect the performance characteristics. In actual practice, there are many factors which affect the surface roughness as depicted in figure1.

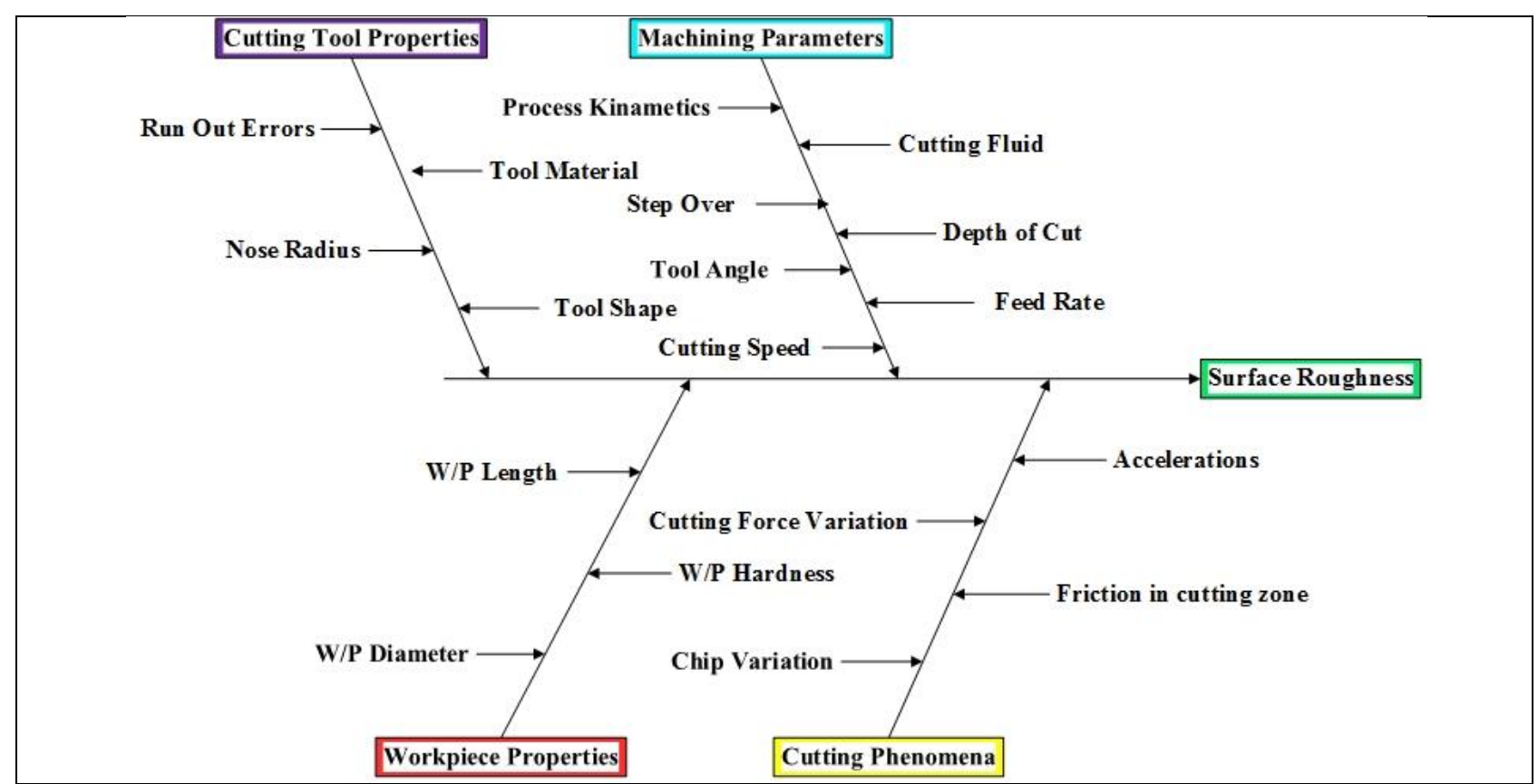

Fig. 1. Factors affecting surface roughness of machined part

These days companies are compelled to focus on developing techniques to minimize machining cost and achieve reasonable production rates to fulfill customer requirements. Therefore, prediction or monitoring of the surface roughness of machined components has been an important area of research.

Dry machining is preferable as it is environmentally benign but friction and cutting temperature generated reduces the tool life and surface quality moreover causes thermally induced geometrical deviations in the machined part. So proper selection of machining parameter is vital. 
Taguchi method is a simple, efficient and systematic approach to optimize the designs for response characteristics. Instead of having to test all possible combinations and full factorial design, the Taguchi method tests a pair of combinations. This allows for the collection of necessary data to determine which parameter is most affecting the product quality with a minimum amount of experimentation, thus saving time and resources.

Several works have been reported in the area of models to predict surface roughness of the machined component. For dry turning operation of cold rolled steel (C62D) a model of surface roughness was developed based on the response surface method to investigates the machining parameters such as feed rate, tool geometry, nose radius, and machining time [2]. The relationship between tool life, surface roughness, and vibration was examined by another group of researchers [3]. The variables that were considered included the cutting speed, feed rate, depth of cut, tool nose radius, tool overhang, approach angle, workpiece length and workpiece diameter The acceleration signals were fed to a FFT analyzer and data were analyzed to produce regression analysis models. In another study [4] under wet cutting conditions, a statistical model was developed to predict the surface roughness estimation in a highspeed flat end milling process, using machining variables such as spindle speed, feed rate, depth of cut, and step over.

Another group of researchers developed an empirical model for predicting the surface roughness in the machining of $\mathrm{A} 356 / \mathrm{SiC} / 20 \mathrm{p}$ composites with the lathe [5]. Use of neural network modeling approach was also made to predict surface roughness and tool wear in turning operation [6]. The objective of [7] was to establish a correlation between cutting velocity, feed, and depth of cut with the surface roughness in turning. For that purpose, a plan of experiments, based on Taguchi techniques, was designed and executed. The results showed that the cutting velocity had the greater influence, followed by the feed and that the error achieved was smaller than that of a geometric theoretical model. In another study [8] group of researchers developed a model of surface roughness prediction for drilling of steel EN 1.0038, using HSS coated TiN drill tools. Their experimental runs were based on the response surface method, and they utilized logarithmic linearized approach for determining the drilling process parameters.

In another investigation researchers [9] included a total of six parameters, namely the workpiece hardness, feed, tool point angle, depth of cut, spindle speed and cutting time to build a model for finish turning operations. Hypothesis testing established the adequacy of the model, while its performance was deemed satisfactory. Feed was also identified as the most important factor along with cutting time. Fuzzy adaptive networks in machining process modeling to predict surface roughness in turning operation were utilized with accuracy and found that this approach is more powerful than the classical regression approach [10]. A part if artificial intelligence, a back propagation neural network model for the prediction of surface roughness in turning operation were also utilized [11]. The effects of turning parameters on the surface roughness have been studied by many researchers [12], [13], [14]. 
The aim of this work is to develop a surface roughness model for turning of DSS (2205) with coated WC-Co tools. The design of experiments was used to plan the experiments, by selecting four controlling factors namely, the cutting speed (A), feed rate (B) and approach angle (C). To know the contribution of influencing factors on surface roughness, ANOVA analysis was carried out. An optimal parameter combination was then obtained by analyzing experimental data. Furthermore, empirical modeling was also carried out to predict response characteristics for the turning process.

\section{Material and Methodology}

In this study, the design of experiment has been used to establish a correlation between the independent variables and the performance characteristics; therefore, the experiments were performed according to a Taguchi (L9).

Since there are a large number of variables controlling the process, some mathematical models are required to represent the process. In order to achieve this, statistical analysis of the experimental results will have to be processed using the analysis of variance (ANOVA). ANOVA is a computational technique that enables the estimation of the relative contributions of each of the control factors to the overall measured response.

\subsection{Design of experiments}

An experimental plan was designed using the Taguchi method, which uses an orthogonal array (OA) to study the entire parametric space with a limited number of experimental runs. The machining parameters (control factors) considered in this study are cutting speed, feed rate, and approach angle. All of them were set at three different levels (see Table 1).

The depth of cut $(0.5 \mathrm{~mm})$ was kept constant throughout the experimentation in the present study.

\begin{tabular}{|l|l|l|l|l|l|}
\hline $\begin{array}{l}\text { Cutting } \\
\text { Parameter }\end{array}$ & \multirow{2}{*}{ Symbol } & \multirow{2}{*}{ Unit } & Level & \\
\cline { 4 - 6 } Cutting Speed & $\mathrm{A}$ & $\mathrm{rpm}$ & 550 & 930 & 1210 \\
\hline Feed Rate & $\mathrm{B}$ & $\mathrm{mm} / \mathrm{rev}$ & 0.05 & 0.20 & 0.36 \\
\hline Approach Angle & $\mathrm{C}$ & degree & 60 & 75 & 90 \\
\hline
\end{tabular}

Tab. 1. Cutting factors and their levels

To select an appropriate orthogonal array of experiments, the total degrees of freedom for the orthogonal array should be equal to or greater than of the machining parameters. The selected OA employed in this study fulfill this requirement.

The experimental layout for cutting parameters using the L9(34) orthogonal array along with response is shown in Table 2. 


\begin{tabular}{|l|l|l|l|l|}
\hline $\begin{array}{l}\text { Experiment } \\
\text { No. }\end{array}$ & \multicolumn{3}{l|}{ Cutting Parameter Level } & Response Parameter \\
\cline { 2 - 5 } & $\begin{array}{l}\text { Cutting } \\
\text { Speed }\end{array}$ & Feed Rate & $\begin{array}{l}\text { Approach } \\
\text { Angle }\end{array}$ & Surface Roughness $(\mu \mathrm{m})$ \\
\hline 1 & 1210 & 0.2 & 60 & 2.431 \\
\hline 2 & 550 & 0.2 & 75 & 2.045 \\
\hline 3 & 930 & 0.05 & 75 & 1.531 \\
\hline 4 & 1210 & 0.36 & 75 & 9.244 \\
\hline 5 & 550 & 0.36 & 90 & 7.026 \\
\hline 6 & 930 & 0.36 & 60 & 8.879 \\
\hline 7 & 930 & 0.2 & 90 & 2.558 \\
\hline 8 & 550 & 0.05 & 60 & 1.098 \\
\hline 9 & 1210 & 0.05 & 90 & 1.645 \\
\hline
\end{tabular}

Tab. 2. Experimental layout using an L9(34) orthogonal array

\subsection{Cutting tool and Work material}

The work material selected in this investigation is DSS (2205). The chemical composition of the alloy with EDX analysis is shown in Figure 2.
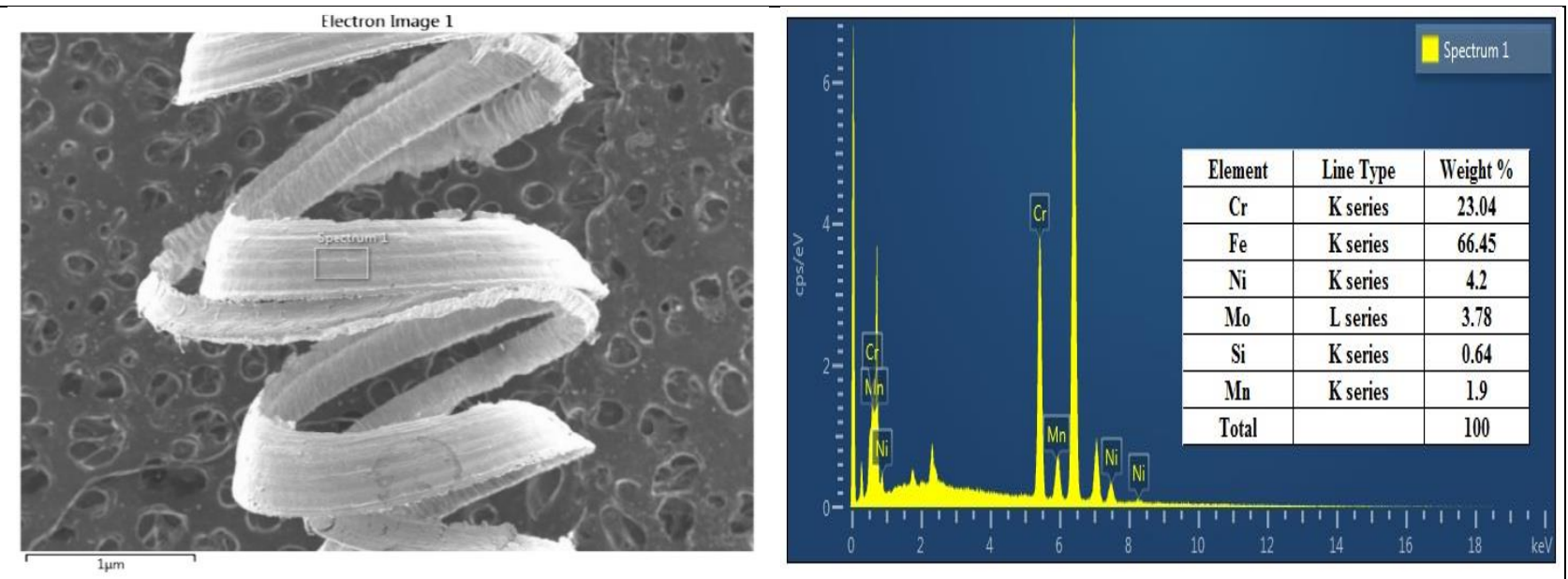

Fig. 2. EDX of workpiece material

A commercially available DSS rod with a $25 \mathrm{~mm}$ diameter was used to perform turning experiments. Before performing experiment rod was grooved to distinguish work area from each other (each having $20 \mathrm{~mm}$ length) for longitudinal turning operation. A thin layer was removed from its surface to the obtained fresh cylindrical surface. After that experimental trials were performed as per L9(34) orthogonal array.

\subsection{Machine tool and Instrument used}

Turning operations were performed on heavy duty lathe machine NH22 (HMT make) as shown in figure 3(a) below. A commercially available coated WC-Co cutting inserts TNMG 160404 FM TN8135 (Widia make) were used for experimentation. It has a triangular shape with $60^{\circ}$ geometry and $0.4 \mathrm{~mm}$ nose radius. A tool holder MTJNR 2020K16 (Widia make), was used. 
Pawan, K. \& Misra, J. P.: A Surface Roughness Predictive Model for DSS Longitu...

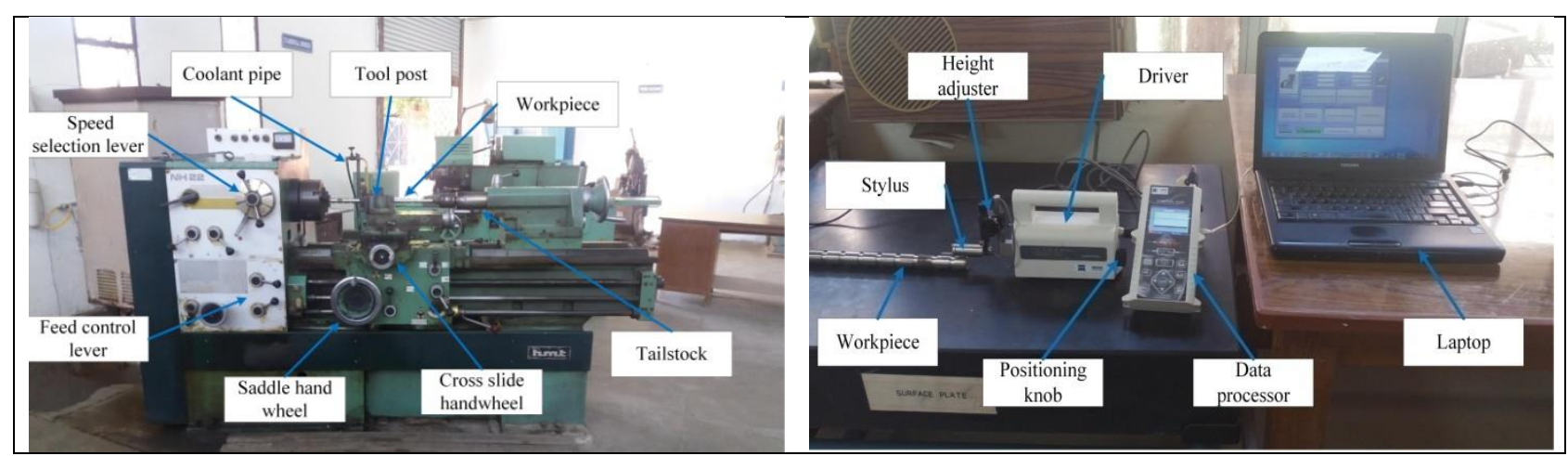

Fig. 3. (a) Machine tool and (b) Surface roughness tester

The roughness average $(\mathrm{Ra})$ of the surface after the turning process were measured by a surface analyzer of SURFCOM FLEX 114 (Carl Zeiss, make). Cut off length $(\lambda c)$ of $2.5 \mathrm{~mm}$ has been used for calculating the surface measurement value along the machined workpiece. Two sampling readings were taken on each machined workpiece and the average of two sampling readings was taken as a final surface roughness measurement value.

\section{Results and discussion}

In this study, the effects of sources of variation (i.e. cutting speed, feed rate and approach angle) on response characteristic (surface roughness) were studied. A confidence interval of $95 \%$ has been used for the analysis. Figure 4 representing the main effect of different machining regime. One can easily depict from the figure 4 that feed rate is a most influential factor affecting the surface roughness in this case.

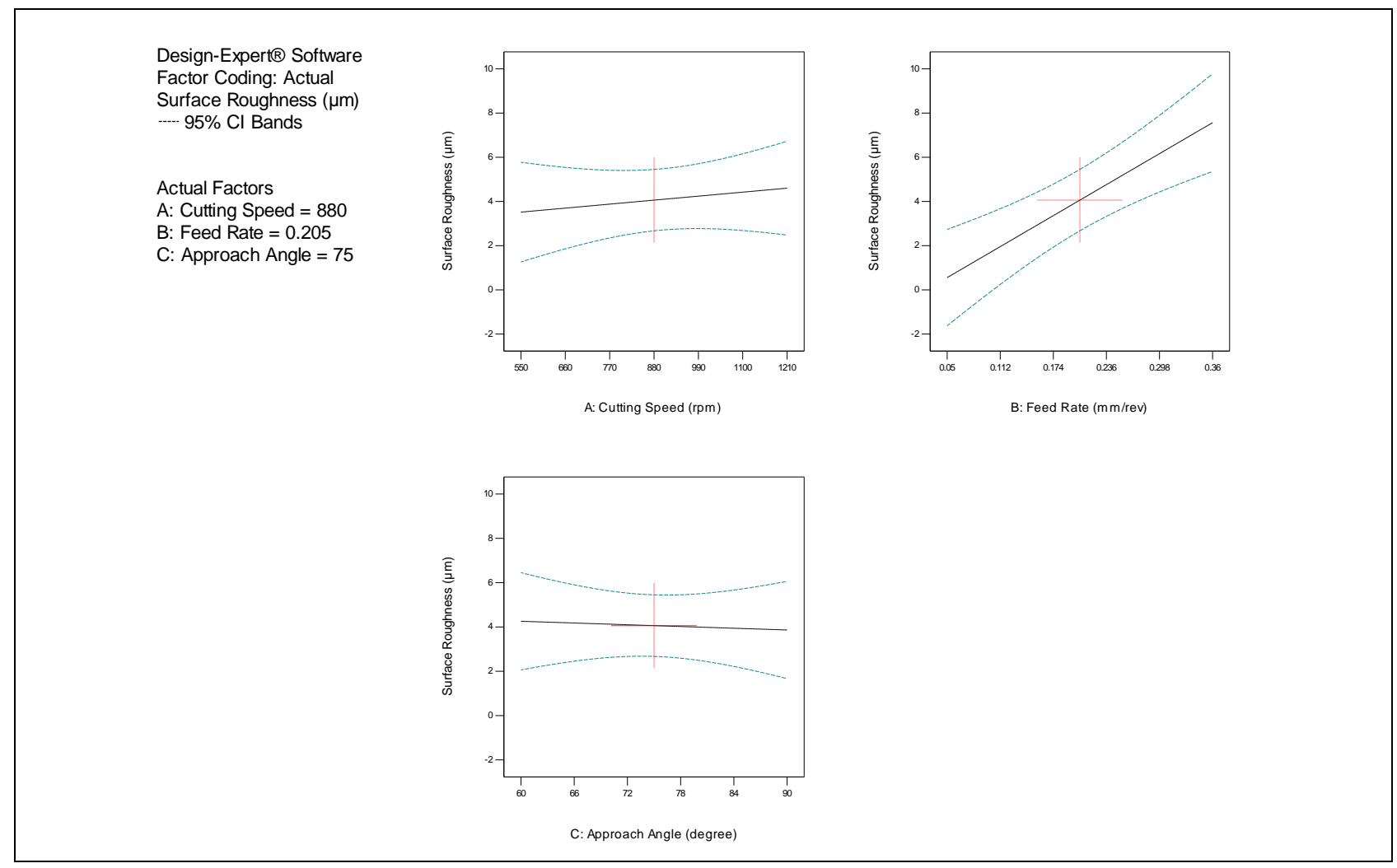

Fig. 4. Main effect plots for surface roughness 


\subsection{Analysis of Variance (ANOVA)}

Analysis of the experimental data was carried out using statistical software Design Expert. Analysis of variance (ANOVA) was performed to determine the influence of input parameters on the output response variables. The results of Taguchi experiments were elaborated and modeled here with statistical significance for the predictive model.

\begin{tabular}{|c|c|c|c|c|c|c|c|}
\hline Source & $\begin{array}{l}\text { Sum of } \\
\text { Squares }\end{array}$ & dof & $\begin{array}{l}\text { Mean } \\
\text { Square }\end{array}$ & \begin{tabular}{|l} 
F \\
Value
\end{tabular} & \begin{tabular}{|l|} 
p-value \\
Prob > F
\end{tabular} & $\begin{array}{l}\text { Contribution } \\
(\%)\end{array}$ & Remarks \\
\hline Model-1 & 75.76 & 3 & 25.25 & 9.64 & 0.0161 & & Significant \\
\hline $\begin{array}{l}\text { A-Cutting } \\
\text { Speed }\end{array}$ & 1.77 & 1 & 1.77 & 0.68 & 0.4481 & 1.99 & - \\
\hline B-Feed Rate & 73.76 & 1 & 73.76 & 28.14 & 0.0032 & 83.01 & Significant \\
\hline $\begin{array}{l}\text { C-Approach } \\
\text { Angle }\end{array}$ & 0.23 & 1 & 0.23 & 0.088 & 0.7782 & 0.26 & \\
\hline Residual & 13.10 & 5 & 2.62 & & & 14.74 & \\
\hline Cor Total & 88.86 & 8 & & & & & \\
\hline Model-2 & 0.52 & 3 & 0.17 & 88.57 & $<0.0001$ & & Significant \\
\hline $\begin{array}{l}\text { A-Cutting } \\
\text { Speed }\end{array}$ & 0.022 & 1 & 0.022 & 11.17 & 0.0205 & 4.15 & Significant \\
\hline B-Feed Rate & 0.49 & 1 & 0.49 & 250.63 & $<0.0001$ & 92.45 & Significant \\
\hline \begin{tabular}{|l|} 
C-Approach \\
Angle
\end{tabular} & $\begin{array}{l}7.634 \mathrm{E}- \\
003\end{array}$ & 1 & \begin{tabular}{|l}
$7.634 \mathrm{E}-$ \\
003
\end{tabular} & 3.92 & 0.1045 & 1.44 & \\
\hline Residual & $\begin{array}{l}9.730 \mathrm{E}- \\
003\end{array}$ & 5 & $\begin{array}{l}1.946 \mathrm{E}- \\
003\end{array}$ & & & 1.84 & \\
\hline Cor Total & 0.53 & 8 & & & & & \\
\hline
\end{tabular}

Tab. 3. ANOVA for Means of SR (Model-1 and Model-2)

A confidence interval of $95 \%$ has been used for the analysis. For both developed models, the result of ANOVA analysis is presented in Table 3. The analysis revealed the contribution of different input variables, which were found to be cutting speed (4.15\%), feed rate $(92.45 \%)$ and approach angle $(1.44 \%)$ for the developed model (Model-2). The residual contribution is only $1.84 \%$ which statistically permissible.

\subsection{Empirical modelling}

Regression is a technique for investigating functional relationship between output and input decision variables of a process and may be useful for manufacturing process data description, parameter estimation and control [15]. The criteria for fitting the best line through the data in simple linear regression is to minimize the sum of squares of residuals between the measured values of response and the values of response calculated with the regression model. The linear fit is expressed as,

$$
y=a_{o}+a_{1} x
$$

Where $\mathrm{y}$ is the value of response and $\mathrm{x}$ is the value of the variable. 
Pawan, K. \& Misra, J. P.: A Surface Roughness Predictive Model for DSS Longitu...

It is clearly observed that the feed rate (B) strongly affects surface roughness parameter Ra. This input parameter has an increasing effect that should be expected. It is well known that the theoretical geometrical surface roughness is primarily a function of the feed rate for a given nose radius and varies with the square of the feed rate value.

The well-known equation for modelling surface roughness is:

$$
R_{a}=\frac{f^{2}}{32 r_{e}}
$$

where $\mathrm{Ra}$ is surface roughness $(\mathrm{mm}), \mathrm{f}$ is feed rate $(\mathrm{mm} / \mathrm{rev})$, re is tool nose radius $(\mathrm{mm})$. But this model found inadequate to predict the surface roughness value for the present study. So there developed a need for better predictive model. The two models were developed as per "(3)" and "(4)". The empirical equations of the fitted models for the quality characteristics are as follows:

$$
R a=-1.03697+1.64127 E-003 A+22.61593 B-0.013100 C
$$

$(\text { Ra) })^{-0.71}=1.23667-1.81676 E-004 A-1.83908 B-2.37799 E-$ $003 C$

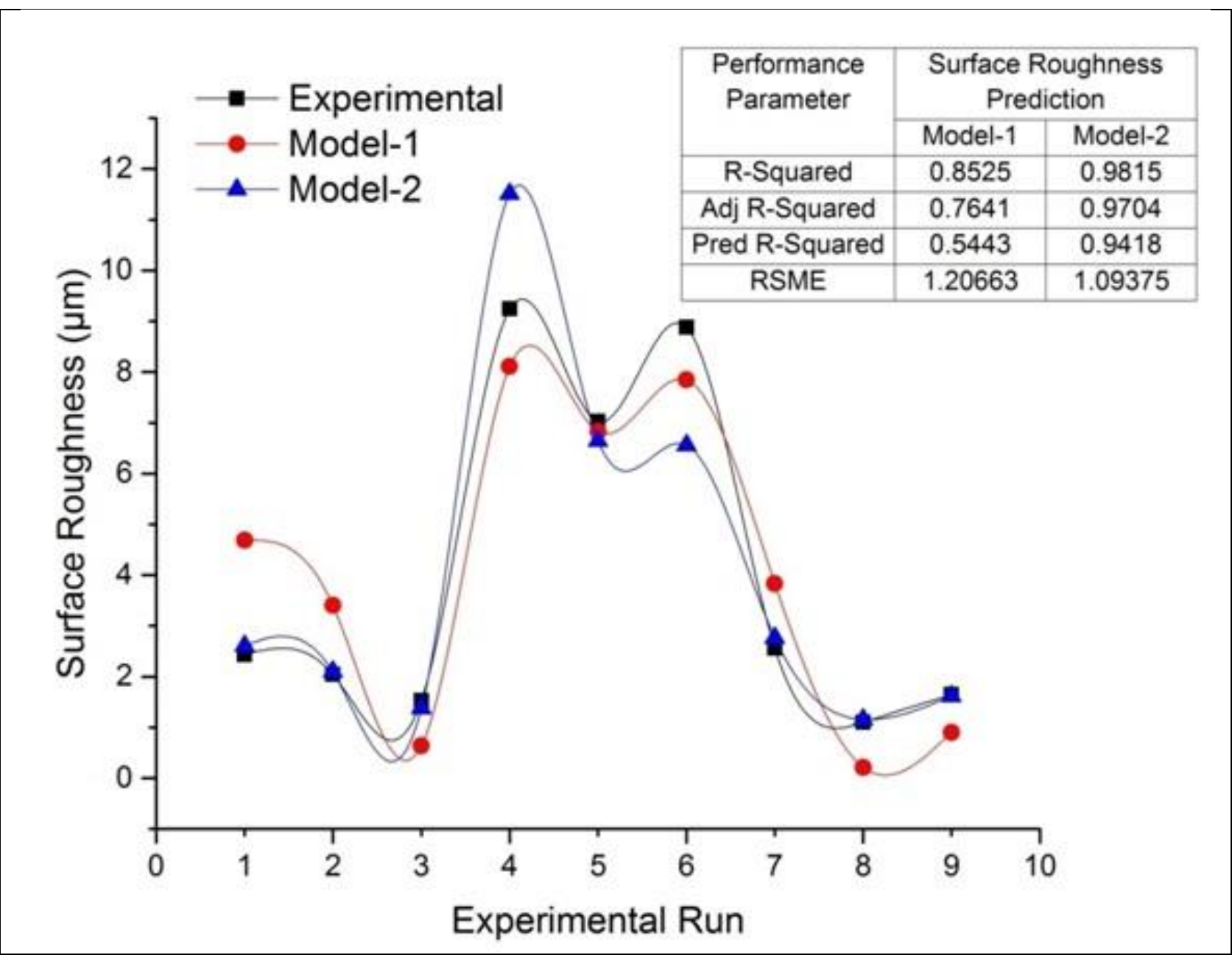

Fig. 5. Experiential Vs Predicted surface roughness 
From the linear regression models developed for surface roughness prediction, it is found that the Model-2 (98.15\%) is more adequate than Model-1 $(85.25 \%)$ for surface roughness prediction. The regression plot obtained during the generation of regression models for SR is shown in Fig. 5.

The R-square value which is also known as "coefficient of determination" ranges between 0 and 1. Higher is the R-Square, better is the predicted response.

The normal probability plot of the residuals for the Model-1 and Model-2 is shown in figure 6. As it appears that data point in case of Model-2 in comparison to Model-1 follow a straight line with the maximum no of points lying near the best fitted straight line.

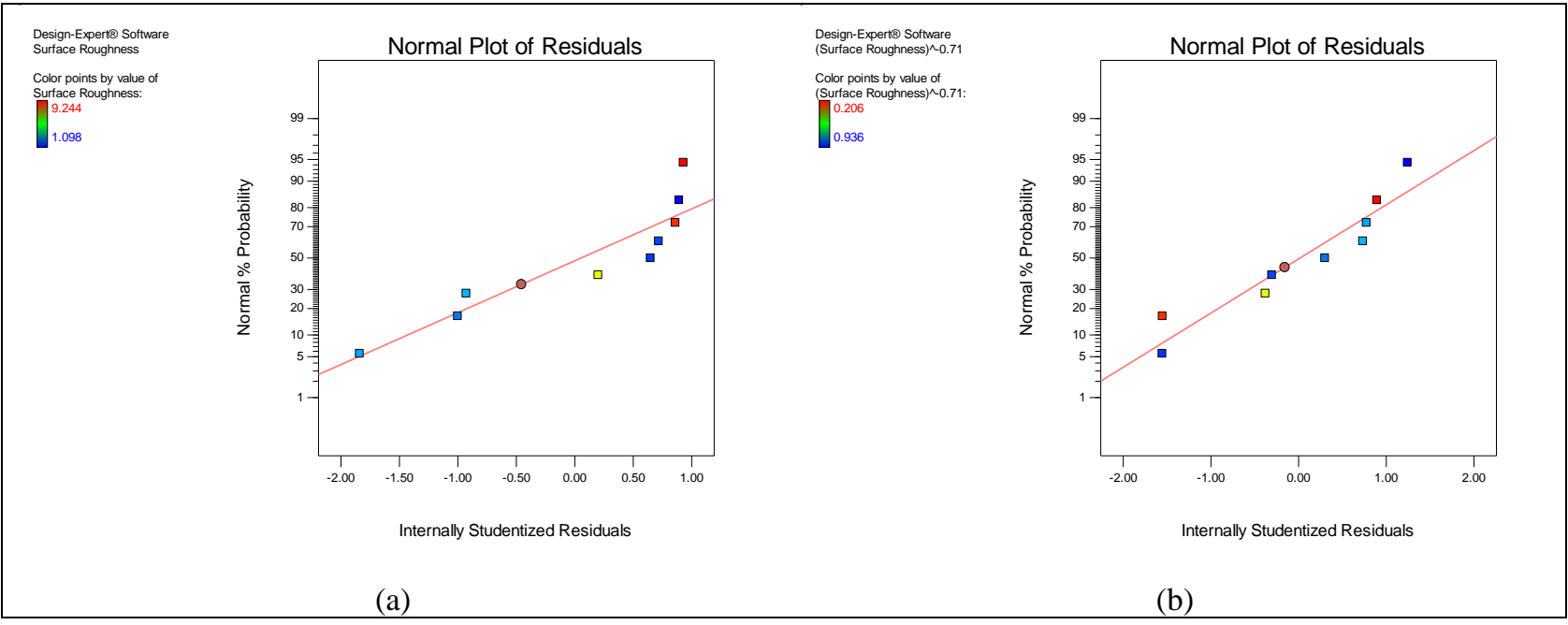

Fig. 6. Normal probability plot of the residuals for (a) Model-1 and (b) Model-2

Figure (7) reprinting the residuals versus fits graph for the both developed models. It shows that the residuals are scattered randomly about zero and there is no pattern and there exists no outlier which adversely affects models if exists.

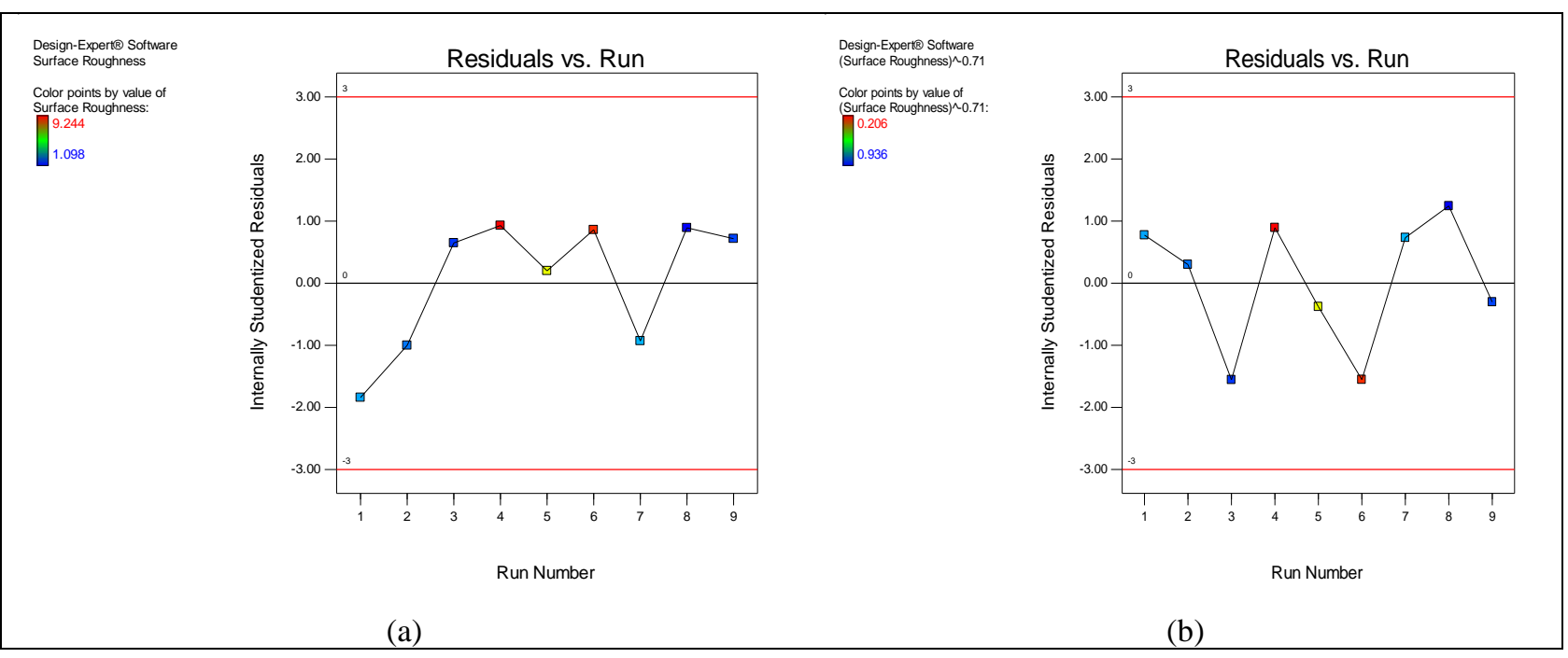

Fig. 7. Residual plot of (a) Model-1 and (b) Model-2 
The graph shown in figure 8. below is representing the efficiency of both empirical models developed so far. RSME of Model-2 was found lower than Model-1 representing the better prediction efficiency.

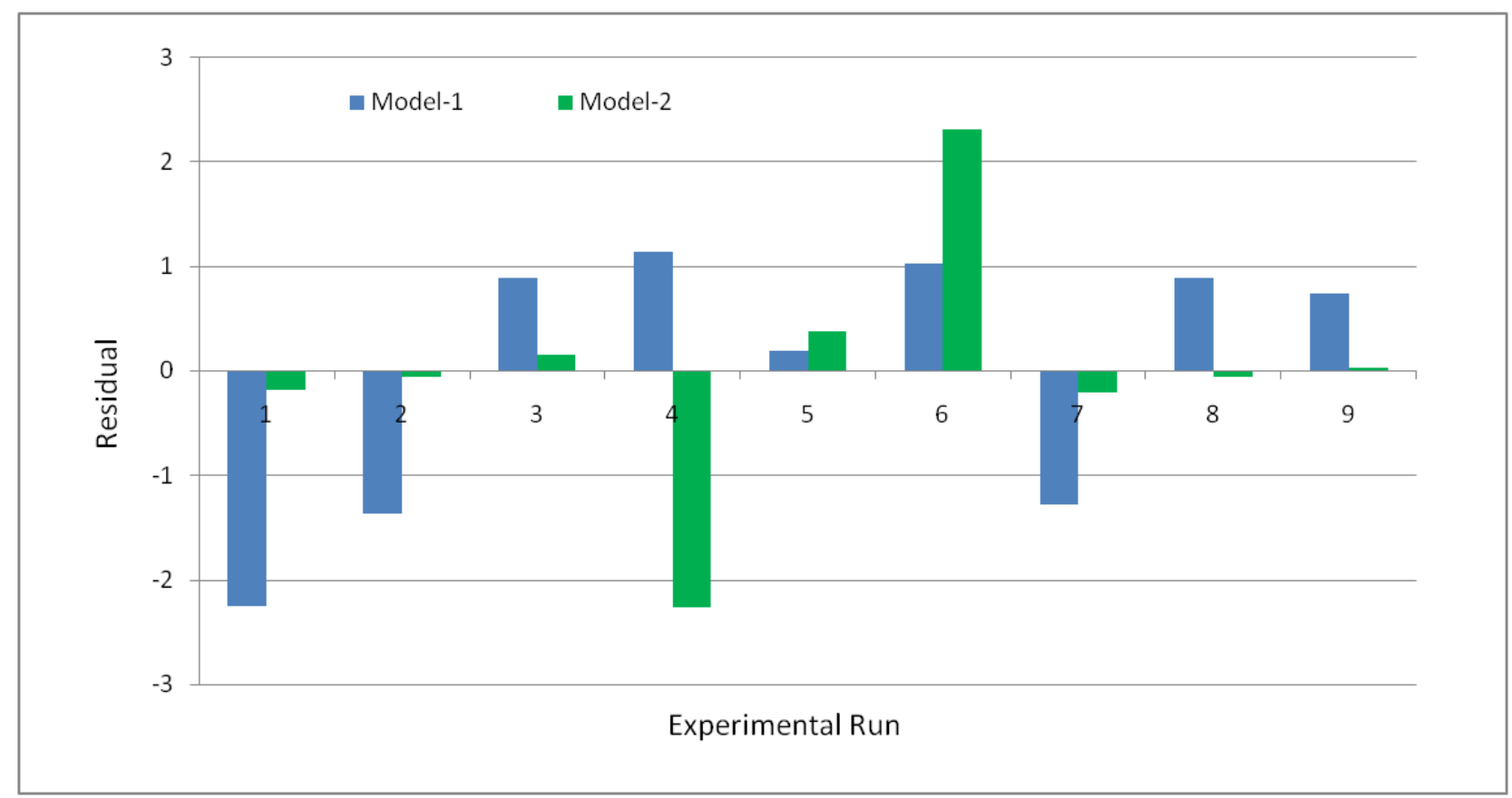

Fig. 8. Residual plot of surface roughness models

\section{Conclusion}

Surface roughness of machined component plays a significant role during its operational life. So, prediction of it becomes quite important as it is dependent on input process variables such as cutting speed, feed rate, depth of cut etc. The investigations of this study indicate that the parameters cutting speed and feed rate are the primary influencing factors, which affect the surface finish.

The results also indicate that feed rate is the dominant factor affecting the surface roughness, followed by the cutting speed. Using different statistical tools Model-2 was developed and has been found very good to represent the turning process for surface roughness prediction of DSS turned part. This model would be helpful in selecting the cutting conditions for the required surface quality. But in this study effect of tool nose radius is not investigated furthermore optimization of the turning process can also be fulfilled by using this model for future work.

\section{References}

Olsson, J., \& Snis, M. (2007). Duplex-A new generation of stainless steels for desalination plants. Desalination, Vol. 205, No. (1-3), 2007, pp.104-113, ISSN: 00119164, https://doi.org/10.1016/j.desal.2006.02.051.

Qehaja, N., Jakupi, K., Bunjaku, A., Bruçi, M., \& Osmani, H. (2015). Effect of machining parameters and machining time on surface roughness in dry turning process. 
Procedia Engineering, Vol. 100, No. 1-3, 2015, pp.135-140, ISSN: 1877-7058, https://doi.org/10.1016/j.proeng.2015.01.351

Abouelatta, O. B., \& Madl, J. (2001). Surface roughness prediction based on cutting parameters and tool vibrations in turning operations. Journal of materials processing technology, Vol. 118, No. 1-3, 2001, pp.269-277, ISSN: 0924-0136, https://doi.org/10.1016/S0924-0136(01)00959-1

Ozcelik, B., \& Bayramoglu, M. (2006). The statistical modeling of surface roughness in high-speed flat end milling. International Journal of Machine Tools and Manufacture, Vol. 46, No. 12-13, 2006, pp.1395-1402, ISSN: 0890-6955, https://doi.org/10.1016/j.ijmachtools.2005.10.005

Palanikumar, K., Muthukrishnan, N., \& Hariprasad, K. S. (2008). Surface roughness parameters optimization in machining A356/SiC/20p metal matrix composites by PCD tool using response surface methodology and desirability function. Machining Science and Technology, Vol. 12, No. 4, 2008, pp.529-545, ISSN: 1532-2483, https://doi.org/10.1080/10910340802518850

Özel, T., \& Karpat, Y. (2005). Predictive modeling of surface roughness and tool wear in hard turning using regression and neural networks. International Journal of Machine Tools and Manufacture, Vol. 45, No. 4-5,2005, pp.467-479, ISSN: 0890-6955, https://doi.org/10.1016/j.ijmachtools.2004.09.007

Davim, J. P. (2001). A note on the determination of optimal cutting conditions for surface finish obtained in turning using design of experiments. Journal of materials processing technology, Vol. 116, No. 2-3, 2001, pp.305-308, ISSN: 0924-0136, https://doi.org/10.1016/S0924-0136(01)01063-9

Zhujani, F., Qehaja, N., Abdullahu F., \& Bruçi, M (2016). Mathematical Modelling of Surface Roughness for Evaluating the Effects of Cutting Parameters in Drilling Process, Proceedings of the 27th DAAAM International Symposium, Austria , ISSN 1726-9679, ISBN 978-3-902734-08-2, B. Katalinic (Ed.), pp.0195-0202, Published by DAAAM International, Vienna, DOI: 10.2507/27th.daaam.proceedings.029

Wang, X., \& Feng, C. X. (2002). Development of empirical models for surface roughness prediction in finish turning. The International Journal of Advanced Manufacturing Technology, Vol. 20, No.5, 2002, pp.348-356, 1433-3015, https://doi.org/10.1007/s001700200162

Jiao, Y., Lei, S., Pei, Z. J., \& Lee, E. S. (2004). Fuzzy adaptive networks in machining process modeling: surface roughness prediction for turning operations. International Journal of Machine Tools and Manufacture, Vol. 44, No. 15, 2004 pp.1643-1651, ISSN: 0890-6955, https://doi.org/10.1016/j.ijmachtools.2004.06.004

Pal, S. K., \& Chakraborty, D. (2005). Surface roughness prediction in turning using artificial neural network. Neural Computing \& Applications, Vol. 14, No. 4, 2005 pp.319-324, ISSN1433-3058, https://doi.org/10.1007/s00521-005-0468-x

Aslan, E., Camuşcu, N., \& Birgören, B. (2007). Design optimization of cutting parameters when turning hardened AISI 4140 steel (63 HRC) with Al2O3+ TiCN 
Pawan, K. \& Misra, J. P.: A Surface Roughness Predictive Model for DSS Longitu... mixed ceramic tool. Materials \& Design, Vol. 28, No. 5, 2007 pp.1618-1622. ISSN: 0261-3069, https://doi.org/10.1016/j.matdes.2006.02.006

Nalbant, M., Gökkaya, H., \& Sur, G. (2007). Application of Taguchi method in the optimization of cutting parameters for surface roughness in turning. Materials \& Design, Vol. 28, No. 4, 2007, pp.1379-1385, ISSN: 0261-3069, https://doi.org/10.1016/j.matdes.2006.01.008

Yang, W. P., \& Tarng, Y. S. (1998). Design optimization of cutting parameters for turning operations based on the Taguchi method. Journal of materials processing technology, Vol. 84, No. 1-3, 1998, pp.122-129, ISSN: 0924-0136, https://doi.org/10.1016/S0924-0136(98)00079-X

Montgomery, D. C. (2017). Design and analysis of experiments. John Wiley \& Sons, ISBN: $9781118146927,1118146921$. 